\title{
KEBUTUHAN KENDARAAN ANGKUTAN TANDAN BUAH SEGAR KELAPA SAWIT DI PT. TRITUNGGAL SENTRA BUANA
}

\section{THE NEED FOR TRANSPORTATION VEHICLES FOR OIL PALM FRESH FRUIT BUNCHES IN PT. TRITUNGGAL SENTRA BUANA)}

\author{
Vinky Kristian ${ }^{1}$, Rossy Mirasari ${ }^{1 \star}$, Roby ${ }^{1}$ \\ ${ }^{1}$ Politeknik Pertanian Negeri Samarinda, Kampus Gunung Panjang, Jl. Samratulangi, \\ Samarinda, Indonesia \\ *corresponding rossymalik678@gmail.com
}

\begin{abstract}
This research is motivated by the need to ensure the availability of Fresh Fruit Bunches (FFB) in a timely manner and in fresh condition, if must be supported by the availability of other resources such as labor, harvesting equipment and tranportation vehicles. The purpose of this study was compre the needs and realization of the number of vehicles transporting FFB PT. Tritunggal Sentra Buana.The method used in this research is a field survey. Field survey conducted to collect data related to field conditions. This research data uses primary data and secondary data. Primary data in the from of calibration from and the result of the calculation of the need for FFB units and secondary, data in the form of production data and FFB transportation data. The availability of FFB transporting vehicles has met the needs of earch afdeling having 3 units of vehicles. The number of unit needed per day for branch 1 and departement 2 is2 units per day. At PT. Tritunggal Sentra Buana has 19 units of FFB transporting vehicles, each of which smoothness of the FFB transportation process is road conditions and road maintenance. At PT. Tritunggal Sentra Buana routinely carries out road maintenance such as hardening the nets that the unit passes throught and pruning the fronds.
\end{abstract}

Keywords: Vehicle needs, Transportation, FFB

\section{PENDAHULUAN}

Kelapa sawit (Elais guineensis Jacq.) sangat penting bagi Indonesia. Selama kurun waktu 20 tahun terakhir kelapa sawit menjadi komoditas andalan ekspor dan komoditas yang diharapkan dapat meningkatkan pendapatan dan harkat petani pekebun serta transmigran di Indonesia, beberapa tahun terakhir banyak bermunculan pabrik pengolahan minyak mentah maupun industri oleokimia yang menggunakan bahan baku yang berasal dari minyak kelapa sawit (Pardamean, 2008).

TBS merupakan bahan baku pembuatan CPO. Untuk menjamin tersedianya TBS secara tepat waktu dan dalam kondisi segar, maka harus ditunjang oleh ketrsediaan sumber daya lainnya seperti tenaga kerja, peralatan dan juga kendaraan pengangkutannya.

Pengangkutan TBS merupakan bagian dari rangkaian proses produksi minyak sawit. Jika buah kelapa sawit masuk pabrik kelapa sawit (PKS) dalam jangka waktu lebih dari 24 jam setelah buah tersebut dipanen, maka dapat disebut buah restan, dan buah restan banyak mengandung ALB yang tinggi (Dhani,2014).

Apabila proses pengangkutan ini dapat berjalan dengan lancar, maka manfaat-manfaat yang diperoleh antara lain ALB produksi harian 2-3 \% mempengaruhi kelancaraan atau kapasitas pengolahan pabrik, mendukung TBS di lapangan, dan menghemat biaya pengangkutan seminimal mungkin (Abidin, 2017). 


\begin{abstract}
Penyediaan sarana pengangkutan
buah menjadi penting dan harus dikoordinasikan secepat mungkin dan paling lambat pada pagi hari sebelum panen dan produksi yang diangkut ke pabrik sudah diinformasikan dan diketahui jumlah kebutuhan kendaraan dan jam mulai muat tandan dari $\mathrm{TPH}$ (Siswadi,2016).
\end{abstract}

Alat yang digunakan untuk mengangkut TBS dari kebun ke pabrik, diantaranya lori, traktor gandeng, atau dump truck. Kebutuhan kendaraan angkut buah dapat dihitung berdasarkan estimasi produksi panen puncak (peak crop) dan panen rendah (low crop). Kebutuhan truk disesuaikan juga dengan kondisi jalan, kapasitas truk, jarak lokasi panen dengan pabrik, waktu pemuatan yang diperlukan, kapasitas truk, dan lama pembongkaran (Pardamean,2017).

Ada empat hal yang menjadi sasaran kelancaran transportasi TBS menurut pahan (2011), yaitu menjaga asam lemak bebas atau free fatty acid (FFA) yang berhubungan dengan mutu produksi akhir, kapasitas atau kelancaran pengolahan di PKS, keamanan TBS di lapangan dan biaya transportasi yang minimum. Jika transportasi TBS tidak lancar, maka akan terjadi penghambatan pengangkutan TBS ke PKS sehingga sasaran diatas tidak tercapai.

Tujuan dari penelitian ini adalah untuk membandingkan kebutuhan dan realisasi jumlah unit kendaraan pengangkutan TBS di PT. Tritunggal Sentra Buana.

\section{METODOLOGI}

\section{Waktu dan Tempat Penelitian}

Penelitian ini dilaksanakan di PT. Tritunggal Sentra Buana Estate 1 afdeling 1 dan afdeling 2 yang beralamatkan Desa Saliki, Kecamatan Muara Badak, Kabupaten Kutai Kartanegara, Provinsi Kalimantan Timur. Waktu penelitian dilakukan pada tanggal 9 September- 9 Desember 2020 meliputi observasi ke lapangan dan pengambilan data.

\section{Alat dan Bahan}

Alat yang digunakan yaitu alat tulis, kamera, kalkulator dan laptop, sedangkan bahan yang digunakan yaitu form kalibrasi unit, data realisasi produksi dan data pengangkutan TBS ke PMKS.

\section{Metode Pengambilan Data}

Metode pengambilan data yang digunakan dalam penelitian ini adalah data primer dan data sekunder. Dalam penelitian ini peneliti mengumpulkan data primer dengan menggunakan observasi. Pelaksanaan penelitian kebutuhan kendaraan angkut TBS ini dilakukan dengan menggunakan form kalibrasi kendaraan angkut TBS yang telah dibuat. Dalam penelitian ini peneliti menggunakan data-data histori perusahaan, yaitu data realisasi produksi, jumlah unit harian kendaraan yang akan dihitung ialah jumlah unit untuk setiap afdeling, karena setiap afdeling mempunyai kondisi yang berbeda, baik dari rencana produksi, jarak, maupun waktu tempuhnya.

Proses perhitungan kebutuhan kendaraan TBS berdasarkan Hudori (2016), dilakukan melalui tahapan sebagai berikut

a. Menghitung kapasitas angkut kendaraan per trip yaitu:

Kapasitas angkut $=\frac{\text { jumlah TBS yang diangkut }}{\text { Jumlah trip angkutan }}$

b. Menghitung jarak tempuh kendaraan per trip yaitu:

Jarak tempuh pertrip $=\frac{\text { Jumlah jarak tempuh }}{\text { jumlah trip angkutan }}$

c. Menghitung produksi harian dengan persamaan:

Produksi harian $=\frac{\text { Produksi bulanan }}{\text { Jumlah hari kerja }}$

d. Menghitung kebutuhan trip harian kendaraan persamaan:

Jumlah trip harian $=\frac{\text { Produksi harian }}{\text { Kapasitas angkut }}$ 
e. Menghitung kebutuhan waktu tempuh harian kendaraan:

Waktu tempuh harian $=$ Jumlah trip harian $\mathrm{x}$ Waktu tempuh pertrip

f. Menghitung jumlah unit harian kendaraan:

Jumlah unit harian $=\frac{\text { Waktu tempuh harian }}{\text { Jam kerja harian }}$

Jumlah unit harian kendaraan yang akan dihitung ialah jumlah unit untuk setiap afdeling. Karena setiap afdeling mempunyai kondisi yang berbeda, baik dari produksi, jarak, maupun waktu tempuhnya. Dengan ini kebutuhan total kendaraan setiap harinya dapat dihitung secara akurat.

\section{Prosedur Kerja}

Pelaksanaan penelitian ini terdiri dari tiga tahap utama yaitu, persiapan, pengambilan data dan pengolahan data. Adapaun uraian penelitian sebagai berikut:

1. Persiapan alat dan bahan penelitian meliputi form kalibrasi, menentukan afdeling dan kendaraan yang digunakan.

2. Melakukan pegambilan data primer dan data sekunder. Pengambilan data primer diperoleh dari form yang telah dibuat dan observasi langsung. Pengambilan data sekunder yang digunakan yaitu laporan data produksi, data TBS yang diangkut, data trip angkutan.

3. Menghitung data-data yang didapat dan memasukan ke dalam tabel pengolahan data.

\section{Analisis Data}

Analisis data berupa analisis deskriptif. Sebagai analisis statistik yang memaparkan data hasil pengamatan tanpa melakukan pengujian statistik. Data yang tersedia diolah sehingga mendapatkan gambaran yang jelas mengenai fakta dan hubungan antar fenomena yang diteliti. Hasil perhitungan kebutuhan angkut kendaraan TBS dibandingkan dengan data sekunder dari perusahaan.

\section{HASIL DAN PEMBAHASAN}

Dalam penelitian ini data primer yang di dapat dengan melakukan observasi langsung ke lapangan dan kemudian hasil yang di dapat untuk menghitung kebutuhan kendaraan angkut TBS setiap afdeling.

1. Kebutuhan kendaraan angkut TBS setiap afdeling pada bulan September-Desember 2020

Kebutuhan kendaraan angkut TBS diperoleh dari kalibrasi pengangkutan yang telah dilakukan setiap afdelingnya. Dari Tabel 1 perhitungan unit harian afdeling 1 dan afdeling 2 jumlah kapasitas angkut per trip untuk setiap unit ialah sebanyak 6000 kg maksimal, jarak tempuh pertrip untuk afdeling $18,25 \mathrm{~km}$ dan afdeling 2 11,14 km, produksi harian afdeling 1 sebanyak $66,414 \mathrm{~kg}$ dan afdeling 2 sebanyak $47,014 \mathrm{~kg}$, jumlah trip harian afdeling $111 \mathrm{~km}$ dan afdeling 28 trip per harinya, waktu tempuh pertrip pada afdeling 11 jam 2 menit untuk afdeling 21 jam 5 menit, waktu tempuh harian afdeling 111 jam 33 menit dan afdeling 29 jam 4 menit per harinya. Kemudian jumlah unit harian yang digunakan pada bulan september ialah 2 unit per hari.

Pada Tabel 2 dapat dilihat kebutuhan unit harian untuk bulan Oktober kapasitas angkut, jarak tempuh, waktu tempuh harian dan jumlah unit harian sama seperti bulan September pada tabel 1. Produksi harian afdeling 1 sebanyak $72,712 \mathrm{~kg}$ dan afdeling 2 sebanyak 51,472 $\mathrm{kg}$, jumlah trip harian 12 trip afdeling 1 dan 9 trip untuk afdeling 2, waktu tempuh pertrip afdeling 11 jam 2 menit untuk afdeling 21 jam 5 menit, waktu tempuh harian afdeling 111 jam 36 menit dan 10 jam 12 menit afdeling 2 . 
Kristian, V., Mirasari, R., Roby .(2021) "Kebutuhan Kendaraan Angkutan Tandan Buah Segar Kelapa Sawit Di PT. Tritunggal Sentra Buana", Jurnal Agriment, 6(2).

Tabel 1. Perhitungan Kebutuhan Unit Harian Bulan September

\begin{tabular}{lccc} 
Pengangkutan TBS bulan September & Afdeling 1 & Afdeling 2 & Satuan \\
\hline Kapasitas Angkut & 6000 & 6000 & $\mathrm{Kg}$ \\
Jarak Tempuh pertrip & 8,25 & 11,14 & $\mathrm{Km}$ \\
Rencana Produksi Harian & 66,414 & 47,014 & $\mathrm{Kg}$ \\
Jumlah Trip Harian & 11 & 8 & Trip \\
Waktu Tempuh Pertrip & $1: 02: 00$ & $1: 05: 00$ & Jam $/$ menit/detik \\
Waktu Tempuh Harian & $11: 33: 00$ & $9: 04: 00$ & Jam $/$ menit/detik \\
Jumlah Unit Harian & 2 & 2 & Unit \\
\hline
\end{tabular}

Tabel 2. Perhitungan Kebutuhan Unit Harian Bulan Oktober

\begin{tabular}{lccc}
\hline \multicolumn{1}{c}{ Pengangkutan TBS bulan Oktober } & Afdeling 1 & Afdeling 2 & Satuan \\
\hline Kapasitas Angkut & 6000 & 6000 & $\mathrm{Kg}$ \\
Jarak Tempuh pertrip & 8,25 & 11,14 & $\mathrm{Km}$ \\
Rencana Produksi Harian & 72,712 & 51,472 & $\mathrm{Kg}$ \\
Jumlah Trip Harian & 12 & 9 & Trip \\
Waktu Tempuh Pertrip & $1: 02: 00$ & $1: 05: 00$ & Jam/menit/detik \\
Waktu Tempuh Harian & $11: 36: 00$ & $10: 12: 00$ & Jam/menit/detik \\
Jumlah Unit Harian & 2 & 2 & Unit \\
\hline
\end{tabular}

Tabel 3. Perhitungan Kebutuhan Unit Harian Bulan November

\begin{tabular}{lccc}
\hline Pengangkutan TBS bulan November & Afdeling 1 & Afdeling 2 & Satuan \\
\hline Kapasitas Angkut & 6000 & 6000 & $\mathrm{Kg}$ \\
Jarak Tempuh pertrip & 8,25 & 11,14 & $\mathrm{Km}$ \\
Rencana Produksi Harian & 70,805 & 50,123 & $\mathrm{Kg}$ \\
Jumlah Trip Harian & 12 & 9 & Trip \\
Waktu Tempuh Pertrip & $1: 02: 00$ & $1: 05: 00$ & Jam/menit/detik \\
Waktu Tempuh Harian & $11: 36: 00$ & $10: 12: 00$ & Jam/menit/detik \\
Jumlah Unit Harian & 2 & 2 & Unit \\
\hline
\end{tabular}

Berdasarkan Tabel 3 kebutuhan unit harian bulan November untuk afdeling 1 dan afdeling 2 kapasitas angkut, jarak tempuh pertrip dan jumlah unit harian sama seperti bulan september dan Oktober. Produksi harian pada afdeling 1 $70,805 \mathrm{~kg}$ dan afdeling 2 sebanyak 50,123 $\mathrm{kg}$, jumlah trip harian afdeling 112 trip dan 9 trip afdeling 2, waktu tempuh pertrip afdeling 11 jam 2 menit untuk afdeling 21 jam 5 menit, waktu tempuh harian afdeling 1 adalah 11 jam 36 menit dan 10 jam 12 menit untuk afdeling 2. 
Dari Tabel 4 kebutuhan unit harian bulan Desember, kapasitas angkut, jarak tempuh pertrip dan jumlah unit harian yang digunakan sama dengan bulan sebelumnya. Produksi harian pada afdeling 1 sebanyak $53,577 \mathrm{~kg}$ dan afdeling 2 sebanyak $38,070 \mathrm{~kg}$ perhari, jumlah trip harian afdeling 110 trip dan afdeling 2 sebanyak 8 trip, waktu tempuh pertrip afdeling 11 jam 2 menit dan untk afdeling 21 jam 5 menit, waktu tempuh harian afdeling 110 jam 3 menit dan afdeling 29 jam 4 menit.

Tabel 4. Perhitungan Kebutuhan Unit Harian Bulan Desember

\begin{tabular}{lccc}
\hline Pengangkutan TBS bulan Desember & Afdeling 1 & Afdeling 2 & Satuan \\
\hline Kapasitas Angkut & & & $\mathrm{Kg}$ \\
Jarak Tempuh pertrip & 6000 & 11,14 & $\mathrm{Km}$ \\
Rencana Produksi Harian & 8,25 & 38,070 & $\mathrm{Kg}$ \\
Jumlah Trip Harian & 10 & 8 & Trip \\
Waktu Tempuh Pertrip & $1: 02: 00$ & $1: 05: 00$ & Jam/menit/detik \\
Waktu Tempuh Harian & $10: 03: 00$ & $9: 04: 00$ & Jam/menit/detik \\
Jumlah Unit Harian & 2 & 2 & Unit \\
\hline
\end{tabular}

Tabel 5. Rekapitulasi Produksi TBS bulan September-Desember 2020

Bulan

$$
\text { Produksi }(\mathrm{kg}) \quad \text { Jumlah Trip Jumlah unit }
$$

Afdeling 1 Afdeling 2 Afdeling 1 Afdeling 2 Afdeling 1 Afdeling 2

\begin{tabular}{ccccccc}
\hline September & $1.708,130$ & $1.471,990$ & 324 & 276 & 84 & 78 \\
Oktober & $1.628,390$ & $1.163,730$ & 323 & 205 & 82 & 71 \\
November & $1.538,370$ & $1.165,00$ & 294 & 215 & 77 & 71 \\
Desember & $1.628,500$ & $1.245,850$ & 298 & 227 & 79 & 77 \\
\hline Rata-Rata & & & & & 3 & 3
\end{tabular}

2. Rekapitulai Produksi TBS bulan September-Desember 2020

Rekapitulasi produksi TBS yang sudah terangkut ke pabrik kelapa sawit bulan September-Desember 2020. Dapat dilihat pada Tabel 5 rekapitulasi produksi TBS bulan September-Desember 2020 afdeling 1 dan afdeling 2 dari jumlah produksi, jumlah trip dan jumlah unit setiap bulan rata-rata jumlah unit yang dibutuhkan adalah 3 unit setiap afdeling. Jumlah produksi harian sangat penting dan ketetapannya akan meningkatkan efesiensi dibidang pemakaian tenaga kerja dan proses pengangkutan, menurut Pahan (2008), tanaman kelapa sawit dapat dipanen pada saat umur tiga atau empat tahun. Produksi yang dihasilkan akan terus bertambah seiring bertambahnya umur dan akan mencapai produksi maksimalnya pada saat tanaman berumur 9-14 tahun, setelah itu produksi yang dihasilkan akan mulai menurun. Umur ekonomis tanaman kelapa sawit berkisar 25-26 tahun. Selain mempengaruhi produksi, umur tanaman 
kelapa sawit juga akan mempengaruhi produktivitas tanaman kelapa sawit akan meningkatkan secara tajam dari umur 7 tahun dan akan mencapai tingkat produktivitas maksimalnya pada umur 15 tahun dan mulai menurun seiring dengan pertambahan umur.

Kebutuhan trip harian pengangkutan TBS dengan realisasi sudah sesuai yaitu dengan kebutuhan perhitungan. Ada beberapa hari jumlah trip menjadi lebih karena jumlah produksi pada hari itu lebih tinggi sehingga membuat trip harian menjadi lebih, seperti produksi pada bulan Oktober tinggi sehingga trip angkutan menjadi over agar buah dapat terangkut ke PKS.

Berdasarkan hasil pengamatan yang dilakukan jarak tempuh untuk memuat buah agar mengoptimalkan jarak tempuh operator saling berkomunikasi dengan mandor 1, mandor panen dan kerani buah untuk mengecek ancak atau blok buah di TPH yang sudah di cek kualitasnya oleh kerani buah hal ini bertujuan agar tidak terjadi pengulangan rute karena buah yang terlambat keluar. Menurut Pujawan dan Mahendrawathi (2010), efesiensi sistem distribusi dapat dilakukan dengan menentukan rute untuk meminimalkan total jarak tempuh dan lama perjalanan sehingga mengoptimalkan penggunaan kapasitas dan jumlah kendaraan yang ada.

Jumlah kebutuhan unit harian setiap afdeling membutuhkan 2 unit untuk mengangkut TBS, perusahaan PT. Tritunggal Sentra Buana estate TSB 1 memiliki 19 unit kendaraan angkut TBS setiap afdelingnya diberikan 3 unit untuk mengangkut TBS, jadi proses pengangkutan di PT. Tritunggal Sentra Buana sudah memenuhi kebutuhan pengangkutan TBS.

\section{Realisasi Kapasitas Angkut TBS}

Realisasi kapasitas angkut TBS didapat dari jumlah TBS yang sudah diangkut ke pabrik dibagi dengan jumlah trip angkutan.

Tabel 6. Alisasi Kapasitas Angkut TBS

\begin{tabular}{ccccc}
\hline \multirow{2}{*}{ Afdeling } & \multicolumn{5}{c}{ Bulan } \\
\cline { 2 - 5 } & $\begin{array}{c}\text { September } \\
(\mathrm{kg})\end{array}$ & $\begin{array}{c}\text { Oktober } \\
(\mathrm{kg})\end{array}$ & $\begin{array}{c}\text { November } \\
(\mathrm{kg})\end{array}$ & $\begin{array}{c}\text { Desember } \\
(\mathrm{kg})\end{array}$ \\
\hline 1 & 5,272 & 5,078 & 5,250 & 5,464 \\
2 & 5,333 & 5,676 & 5,418 & 5,488 \\
\hline
\end{tabular}

Berdasarkan Tabel 6 realisasi kapasitas angkut TBS afdeling 1 pada bulan September $5,272 \mathrm{~kg}$, bulan Oktober $5,078 \mathrm{~kg}$, bulan November $5,250 \mathrm{~kg}$, bulan Desember $5,464 \mathrm{~kg}$ dan kapasitas angkut TBS afdeling 2 bulan September $5,333 \mathrm{~kg}$, bulan Oktober $5,676 \mathrm{~kg}$, bulan November $5,418 \mathrm{~kg}$, bulan Desember $5,488 \mathrm{~kg}$

Berdasarkan hasil pengamatan di lapangan alat angkut TBS yang digunakan adalah dump truk dengan kapasitas angkut 5-6 ton per trip setiap harinya, terkadang dengan beberapa kondisi dilapangan seperti pusingan yang tinggi menyebabkan kegiatan pengangkutan harus melebihi kapasitas hingga mencapai 6-7 ton lebih agar TBS terangkut semua ke pabrik pada hari itu juga. Namun jika proses pengangkutan melebihi kapasitas angkut terus menerus dapat menyebabkan faktor kerusakan seperti alat angkut, jalan dan jembatan. Berkaitan dengan hal tersebut menurut Abidin (2017), hal yang diperhatikan dalam pengangkutan TBS kelapa sawit, 
diantaranya pembatasan kapasitas angkutan truk. Output atau kemampuan rata-rata produktivitas di PT.Tritunggal Sentra Buana perharinya sebanyak 25 Ton/Hari dengan trip rata-rata 4-5 trip untuk 1 unit, ini sudah melalui perhitungan atau kalibrasi dari perusahaan dalam kondisi lapangan yang ringan, sedang dan berat. Semakin cepat proses pengangkutan TBS kelapa sawit dilakukan maka semakin baik.

\section{KESIMPULAN}

Berdasarkan hasil penelitian dapat disimpulkan bahwa ketersediaan unit kendaraan pengangkutan TBS sudah memenuhi kebutuhan. Setiap afdelingnya memiliki 3 unit kendaraan. Jumlah kebutuhan unit perhari yang dibutuhkan afdeling 1 dan afdeling 2 adalah 2 unit perhari, jadi proses pengangkutan sudah memenuhi kebutuhan pengangkutan TBS. Agar proses pengangkutan lancar yaitu memastikan unit yang akan digunakan setiap harinya untuk mengangkut TBS dalam kondisi yang siap beroperasi dan melakukan perawatan rutin kendaraan maupun kondisi jalan menuju pabrik kelapa sawit.

\section{DAFTAR PUSTAKA}

Abidin Z. 2017. 5 Hal yang Perlu Diperhatikan dalam Pengangkutan TBS. http://ptpn1.co.id/artikel/5halyang-perludiperhatikan-

dalampengangkutan-tbs (diunduh 2 juli 2020).

Dhani S.R 2014. Manajemen Panen dan Transportasi Kelapa Sawit (Elais Guineensis Jacq.) Di sungai Bahaur Estate, PT Windu Nabat Indo Abadi, Kalimantan Tengah. Fakultas Pertanian Institut Pertanian Bogor, Bogor .

Hudori, M. 2016. Perencanaan Kebutuhan Kendaraan Angkutan Tandan Buah Segar (TBS) di Perkebunan Kelapa Sawit. Malikussaleh Industrial Enggineering Journal.

Pahan, I. 2008. Panduan Lengkap Kelapa Sawit. Penebar Swadaya. Jakarta
2011. Panduan Lengkap Kelapa Sawit Cetakan 11. Jakarta. Penebar Swadaya

Pardamean. 2008. Panduan Lengkap Pengelolaan Kebun dan Pabrik Kelapa Sawit. Cetakan pertama. PT. AgromMedia Pustaka, Jakarta.

2017. Kupas Tuntas Agribisnis

Kelapa Sawit. Cetakan pertama. Penebar Swadaya. Jakarta Timur.

Pujawan, I.,N., \& Mahendrawathi E.,R. (2010) supply Chain Management. 2nd Ed. Surabaya: Guna Widya.

Siswadi. H. 2016. Panduan Praktis Agribisnis Kelapa Sawit Rakyat Berwawasan Lingkungan. Cetakan pertama. Deepublish. Yogyakarta. 